\title{
UCLA
}

Mester

Title

El día potencial

Permalink

https://escholarship.org/uc/item/96n8p5th

Journal

Mester, 20(1)

Author

Carreras, Julio

Publication Date

1991

DOI

10.5070/M3201014128

Copyright Information

Copyright 1991 by the author(s). All rights reserved unless otherwise indicated. Contact the author(s) for any necessary permissions. Learn more at https://escholarship.org/terms

Peer reviewed 


\section{El día potencial}

El hombre abrió la puerta de su casa y salió a la niebla de la calle. Pensó: "qué pesada está hoy la neblina". Los edificios y la vereda parecían flotar. A esa hora ya había mucho movimiento, de gente que iba y venía, de camiones, taxis y colectivos. Eran las ocho y media.

A dos cuadras, cerca de la esquina, había un prostíbulo. Pensó en la ironía de aquellas muchachas, trabajando a plena luz allí. Enfrente, plazoleta de por medio, había un jardín de infantes. Y entre ambos, al borde de la plazoleta, una parada de colectivos, donde esforzadas amas de casa esperaban con sus bolsas sobreorladas por vegetales, mirando trabajar a las yiritas.

La niebla ocultaba a medias los objetos, como en un sueño. De lejos vio la miniminifalda roja de una de las chicas, asomando. Su compañera permanecía semioculta; se veían las dos cabelleras rubias, a diferente altura, sacudiéndose con los movimientos pásmicos de las mujeres. Aun sin verla del todo reconoció a la de minifalda roja. Era una muchacha muy joven, alta, bonita, de piernas perfectas: digna de figurar entre las gatitas de Porcel. El hombre se dijo que algún día se iba acostar con ella. Lástima que siempre trabajara de mañana. A esa hora a él le era imposible. Se preparó, con una sonrisa interior, a recibir las cotidianas invitaciones de las chicas.

-Buen día-las saludó.

-Buen día, tesoro-contestó la más bajita.

— ¡Papá! . . . ¡Vení! . . ¡ ¡No seas malito! . . ¡ ¡Vení, que te hago gozar como un loco, que te como enterito, papá! . . . - exclamó en chasqueante susurro la gatita que a él le gustaba.

Se sintió halagado por aquel tratamiento, desechando pensar que era el habitual, por parte de las muchachas, hacia todo transeúnte masculino. Entonces fue que sucedió el primer hecho. Cuando iba a posar de nuevo sus ojos en las piernas perfectas, las dos muchachas desaparecieron. Con 
un "flop", como cuando se desinfla un globo, todo el edificio del prostíbulo desapareció.

El hombre se detuvo alelado. Atinó a estirar la mano, para ver si era cierto aquello. No pudo palpar nada. En el espacio que antes ocupaban el flaco edificio de dos plantas y las chicas, ahora se había formado un vacío oscuro, inundado de niebla.

-Estaré soñando .... - pensó el hombre. Y miró hacia el frente, asumiendo un instante el aspecto de quien pide ayuda. Mucha gente esperaba el colectivo. Un grupo de niños jugaban con su maestra, en la plaza. Al parecer nadie había visto lo que sucediera. El mundo estaba en orden; con excepción del prostíbulo y las chicas, todo seguía en su lugar.

Decidió seguir caminando por la vereda neblinosa. La palma de su mano, apretando con exceso la manija del portafolios, empezó a transpirar. Le dieron ganas de fumar. Tentó en el bolsillo de su saco una forma rectangular; la extrajo. No. Era el portadocumentos. ¿No había puesto los cigarrillos en el bolsillo antes de salir? Miró mecánicamente la foto polaroid:

Nombre: Alberto Uno.

Fecha de nac.: 19/09/49

"Nueve, nueve, nueve. Tres veces tres, por tres", pensó. "Veintisiete. Otra vez nueve”. Ah. Ahí estaba el quiosco del gringo Pistarini. Se acercó para comprar cigarrillos. El gringo leía el diario.

— ¿Cómo le va, profesor?-dijo.

-Bien, ¿y usted? Demé un Parisién.

— ¿Vio lo del crimen de La Calera? ¿Sabe quién había sido? ¿Se acuerda del muchachito ese tan elegante, de aquí a la vuelta, el que vivía sobre Lavalleja?-le comentó sin pausa el gringo, ansioso por compartir la noticia. Alberto Uno se interesó.

— ¿Cuál, el buenmocito ese?-averiguó, mientras quitaba la cintita al paquete.

- ¿Ése, ése! ¿Se acuerda que todo el mundo decía, qué buen muchacho, tan educado, los padres deben estar orgullosos, trabajaba y estudiaba abog...

Alberto Uno levantó los ojos, sorprendido por la interrupción. No estaba. El gringo no estaba. ¿Cómo podía ser? Metió la cabeza dentro del local, tratando de no aplastar con el pecho las cajas de caramelos y pastillas, pero no. Verdaderamente no estaba. Le volvió a la mente lo de las prostitutas. ¿Qué estaba pasando? Olvidándose de fumar decidió seguir caminando, aunque con paso lento. Guardó el paquete en el bolsillo del saco.

La calle Rodríguez Peña se poblaba de gente que iba y venía. Era una linda mañana. El sol destellaba, alto ya . . pero esa niebla . . Era extraño que a esa hora se mantuviera. Se solazó mirando a la gente 
presurosa, en la acera de enfrente, por entre el tránsito veloz de doble mano. Una muchacha con falda marrón y medias amarillas. Un viejo flaco, de chistera y flor en el ojal . . . iqué personaje! . . . Un . . ¿ ¿qué pasa? . . . otro desaparecido . . . El gordo monumental, que caminaba haciendo a la gente abrirse a su paso como las olas ante un acorazado ... no estaba. Pero si él lo venía mirando. ¿Y qué sucedía, que la gente no decía nada, nadie ni se mosqueaba? Se detuvo un momento y se tocó la cabeza. Dura de gomina. "Qué carajo pasa", pensó. "Soy pelotudo yo, o qué. Aquí está pasando algo. No me falla la vista, porque a la casa de las yiras la quise tocar, y no había nada".

Siguió caminando, cada vez con menos velocidad. ¿Qué haría? ¿Iría a trabajar o se volvería a su casa? Se hacía tarde. A las nueve y diez tenía la primera hora. Las cosas estaban desapareciendo. Tenía miedo. ¿Y si desaparecía el suelo bajo sus pies? ¿Adónde caería? No, no podía ser. Algo estaba fallando en su mente. Mucho trabajo. Mucha lectura. Pero el argumento le pareció ficticio. Él no trabajaba en exceso. Y lo único que leía aparte de textos resumidos sobre su materia eran historietas. Eso podía ser. El Eternauta. Había leído hacía poco, dos veces, el libro completo del Eternauta. Solano López, Héctor G. Oesterheld. Pero, ¿podía haber influído tanto en su mente? . . . Decidió seguir caminando. Era obstinado. Como cualquiera. Es más fácil ser obstinado que no serlo, pensó. Y vio que desaparecía un auto, y otro, pero siguió. Como los perros alemanes a los que ponían una granada al cuello y se iban hacia los tanques, pensó.

De repente apareció ante sus ojos la magnífica vista del Puente Avellaneda. Anchísimo sobre el río, gente que iba, gente que venía, autos; un mundo bullendo sobre el puente. Dos Córdobas, una de aquel lado, otra, más provinciana, para este lado del puente, pensó . . . qué raro . . .

En ese momento desapareció el puente. Enterito, como si se lo hubiera engullido el aire. No lo podía creer. Superado su temor por la curiosidad, caminó más rápido, para ver qué había sucedido. Llegó al borde mismo del vacío, adonde había estado el puente antes, y nada. Se agachó y tocó ... no había nada. Pero la gente iba y venía, por el vacío, y los autos. Pasó a su lado un muchacho en bicicleta; lo más campante, siguió por sobre el vacío, sin caerse en absoluto. Acompañándolo con la vista lo vio empequeñecerse hasta llegar al otro lado, doblar a la derecha y perderse en la ciudad. Como un conejo hipnotizado por la serpiente se dispuso a probar consigo mismo aquel fenómeno. Acercó un pie al hueco; luego otro . . . y se cayó al abismo. Milagrosamente, logró aferrarse con los dos brazos al borde del pavimento, su mano izquierda se atenazó al pie metálico de la baranda . . . Dos hombres y una señora lo auxiliaron presurosos. Pronto se formó un nutrido grupo a su alrededor. Lo ayudaron a levantarse, la señora le limpiaba el saco con la mano, un hombre decía "no se amontonen, por favor aire, aire", otro decía: "a ver, paren un auto", una 
mujer elegante le preguntó: “¿se siente bien, señor? ¿Quiere que lo llevemos al hospital?" "Es un desmayo nomás, ya le pasó"” decía otro. Le miraban con curiosidad.

-Diganmé, ¿ustedes no ven nada?... en el puente ...-exclamó Alberto Uno, pero algo que detectó en los ojos que le observaban le aconsejó no seguir en esa cuerda. En el acto cambió el discurso:- Me pasa con frecuencia últimamente . . . -dijo-. Mucho trabajo . . . Me agarró un mareo, veía todo borroso . . .- Por suerte, las miradas se tornaron comprensivas.

- ¿Quiere que lo acerquemos hasta su casa? - preguntó la señora elegante. - ¡Gracias, gracias!-replicó Uno-. ¿Ustedes son tan amables! ¡Les agradezco mucho, pero volveré caminando, vivo aquí, a tres cuadras! ¡Gracias!

Caminó presuroso sin mirar a los costados, sin hacer caso a los vacíos cada vez más numerosos que advertía a su paso. Al fin, llegó hasta la puerta de su hogar. Abrió, se dirigió directamente a la habitación. Allí estaba Elena, durmiendo aún sobre la cama ancha. Menos mal. El camisón se le había levantado casi hasta la cintura, su pierna derecha formaba una graciosa " $V$ ", con el flanco interno del pie afirmado sobre la rodilla izquierda, la onda globular de su nalga se difuminaba sobre los inicios del vello puberal, que aureolaba la bella ostra. Sin proponérselo, se encontró adelantando la mano. Bruscamente se detuvo. Tuvo miedo de que ella también desapareciera. Entonces, vestido como estaba, se acostó sin tocarla, a su lado, y puso el portafolios sobre las piernas.

Durmió cinco minutos. Se despertó sobresaltado, pero Elena seguía allí. Apenas había modificado unos grados el escaleno curvilíneo que formaba con sus piernas. En ese momento él se movió. Elena se dio vuelta, y le miró.

- ¿Qué te pasa, loquito? - le preguntó. Los ojos le brillaban, con sorna. Alberto acercó una mano temblorosa, y luego de una larga vacilación, le aferró un pecho. Elena se rio a carcajadas.

El joven físico Gustavo Carré vino a confirmar, con la narración que le hizo su amigo Alberto Uno, cierta presunción teórica sobre la cual venía trabajando desde hacía rato. Es la siguiente:

Los objetos y los seres se desenvuelven en dos planos de existencia, complementarios pero impercibidos hasta el momento por la razón. Éstos son, a saber, los de la materia potencial y de la materia en acción. Para comprensión de Alberto, que era un lego en asuntos de física, le explicó que ambos planos formaban una entelequia, algo comparable a la cinta sin fin que suele ponerse a los contestadores telefónicos, y también, en cierto modo, a la de Moebius. 
En el plano de la materia potencial se desarrollaban los hechos de seres y objetos en proceso de energizarse para la acción, es decir, aquellos hechos que iban a suceder, pero no sucedian aún, más que en carácter de ensayos perfectibles. Así, aquellos hechos podían repetirse una y otra vez, hasta que la carga de energía potencial los capacitase para atravesar el límite sutil que los separaba de la accionalidad (lo que nosotros llamamos comúnmente realidad).

La dimensión del segundo plano, la materia en acción, no necesitaba de explicaciones, pues se trata del que percibimos cotidianamente con nuestra razón.

Volviendo al anterior, al de la materia potencial, Gustavo le dijo que una de las líneas del pensamiento humano se desenvuelve de modo asintótico ${ }^{1}$ con él. Es la de los proyectos, o de la prospección. Cuando nosotros desde la cama, antes de comenzar el día, programamos las actividades que vamos a desarrollar-dijo Gustavo Carré-estamos realizando, sin tener conciencia de ello, una especie de mayéutica entre nuestro pensamiento y la dimensión de la materia potencial.

El día de aquellos sucesos, por una situación extraordinaria-aunque ninguna realmente lo es, según Gustavo, ya que somos un concierto organizado hasta lo infinitesimal por el Gran Cerebro del Universo-tuvo lugar un entrecruzamiento de los dos planos. Por una diacronía de los elementos, Alberto Uno había atravesado la frontera de otra dimensión, al poner el pie fuera del umbral de su casa. Y se había convertido, impensadamente, en el privilegiado testigo de una realidad que ya acariciaban con la imaginación los científicos más avanzados del mundo-sin atreverse a hacerla pública todavía. Tal vez tal transvasamiento se hubiera dado por estar aún Alberto, en ese instante, psicológicamente ubicado en el terreno del sueño, donde es posible que se dé un mayor acercamiento a esa realidad potencial...

-Tal vez-dijo dubitativamente Gustavo Carré-. Ahora, nos tocará a ambos el azaroso papel de Galileos. Por suerte, no existe ya el Tribunal del Santo Oficio de la Inquisición.

-No-dijo Alberto Uno, en el mismo tono-. Pero existe el Borda. ${ }^{2}$

- Julio Carreras

\section{NOTAS}

1. Asintota: Línea matemática que se aproxima constantemente a una curva, pero sin encontrarla en una distancia finita.

2. Hospital psiquiátrico en Buenos Aires, Argentina. 